\title{
Physical Processes at the Shelf Edge in the Northwest Atlantic*
}

\author{
Peter C. Smith and Helmut Sandström \\ Physical and Chemical Sciences Branch, Department of Fisheries and Oceans \\ Bedford Institute of Oceanography, Dartmouth, Nova Scotia, Canada B2Y 4A2
}

\begin{abstract}
Abrupt depth changes at the edges of continental shelves leading to important physical processes in the ocean are described with reviews on the progress in understanding three such processes: (1) interaction of offshore currents and eddies with the continental margin; (2) wind-driven upwelling at the shelf break; (3) generation of internal tides and nonlinear waves by the $M_{2}$ surface tide. Two possible modes of interaction between offshore currents and coastal waters are contrasted. The first is characterized by eddy exchange created by a current guided along the shelf edge (as on the Labrador and Newfoundland shelves or in the United States South Atlantic Bight) while the second involves remote forcing by low-frequency topographic Rossby waves radiated from offshore meanders and rings to the shelf edge. In addition, wind-driven upwelling from depths of $400 \mathrm{~m}$ or more results from moderate $\left(10-15 \mathrm{~m} \mathrm{~s}^{-1}\right)$ but persistent alongshore wind. Complex bathymetry of the shelf may cause anomalously high currents in a fully three-dimensional circulation. Large-amplitude internal waves driven by the $\mathrm{M}_{2}$ surface tide are a ubiquitous feature of the shelf edge circulation. The intense vertical mixing associated with these waves promotes high levels of biological productivity at the shelf edge by continuously supplying nutrients to the surface layers.
\end{abstract}

\section{Introduction}

Abrupt depth changes which characterize the edges of continental shelves lead to interesting and important physical processes in the ocean. Steep bottom slopes are responsible for guiding low-frequency currents along isobaths, for refracting, reflecting and scattering of various wave motions, and for promoting upwelling of deep ocean waters to the shelf (Huthnance, 1981). On the western side of major ocean basins, strong boundary currents, such as the Gulf Stream or Labrador Current, radiate low-frequency energy that impinges on, but rarely crosses, the continental margin because of vorticity constraints associated with the large change in depth (Smith, 1983).

Other important energy sources for shelf edge processes include the barotropic (surface) tide and surface wind stress. In addition, the reduced thermal capacity of shallow shelf seas relative to the deep ocean and the input of fresh water runoff to the shelf may lead to sharp contrasts between coastal and oceanic water masses at the shelf edge. These strong gradients, combined with energetic physical processes, may lead to enhanced mixing and biological productivity. Off the southeastern coast of the USA, the upwelling of deep water at the shelf break, caused by wind and eddy activity along the inshore edge of the Gulf Stream, is considered to be the major source of nutrients to the shelf ecosystem (Atkinson et al., 1982). Similarly, Fournier et al. (1977) suggest that shelfbreak processes are responsible for the observed maxima of biological rates and standing stocks at the edge of the Scotian Shelf. Even in the absence of forcing by energetic offshore currents, as on the Northwest European Shelf, eddy activity associated with the shelfbreak front may promote high rates of cross-shelf mixing (Pingree, 1979) while vertical mixing by internal waves injects nutrients into the euphotic zone.

In the following sections, attention will be focussed on three varieties of shelf edge processes:

(1) interaction of offshore currents and eddies with the topography of the continental margin;

(2) wind-driven upwelling at the shelf break;

(3) generation of internal tides and nonlinear waves by $\mathrm{M}_{2}$ surface tide.

Each section will include a brief account of the historical development of understanding of the particular phenomenon. As in many areas of oceanographic research, advancement in understanding shelf edge processes does not occur steadily but in spurts. The combination of many factors, such as technological change and new ideas, creates conditions for rapid progress followed by slower-paced periods of consolidation of ideas. The past two decades have seen

- Contribution to BIO Review '87, Bedford Institute of Oceanography, Dartmouth, Nova Scotia, Canada. 
renewed worldwide interest and intensive research into shelf edge processes.

\section{Eddy Interactions with the Continental Margin}

There are many possible sources of energy for low-frequency eddy motions near the edge of the continental shelf. Petrie (1983) credits the interaction of transient wind-driven flows with shallow banks for anomalous currents on the outer Scotian Shelf, whereas Pingree (1979) attributes baroclinic eddies bordering the Celtic Sea to hydrodynamic instability of a shelf break front. However, on the western side of ocean basins, a more likely source of eddies are strong western boundary currents. Where the Gulf Stream flows along the shelf edge in the USA South Atlantic Bight, frontal eddies form on the inshore edge of the current and extend into shallow water. North of Cape Hatteras, the Gulf Stream lies farther offshore and large-scale meanders "pinch-off" to form Warm-Core Rings (WCR) which contain vast stores of potential energy (Fig. 1) and are capable of radiating low-frequency Topographic Rossby Waves (TRW) up the continental rise and slope to the shelf edge.

The earliest accounts of eddy currents in the South Atlantic Bight come from ship's logs in the late 1500 s (Brooks and Bane, 1981). However, the first quantitative measurements of the velocity and temperature structures in the surface layers of the Gulf Stream were made by Webster (1961), who characterized the meanders off Onslow Bay as skewed, wavelike oscillations with periods of 4-7 days. Webster's observations, which were made with a bathythermograph (for temperature) and a set of towed electrodes known as a Geomagnetic Electrokinetograph or GEK (for current), have since been considerably augmented by modern measurement devices such as moored current meters, Conductivity Temperature Depth (CTD) profilers, and radiation thermometers carried by satellites or aircrafts.

In synthesizing results of extensive field programs off Florida and the Carolinas, Lee et al. (1981) and Bane et al. (1981) have described the circulation of frontal eddies that produce warm salty tongues of Gulf Stream water that fold backwards along the inshore edge of the Stream to enclose a core of rich upwelled water. With cross-stream scales of $10 \mathrm{~km}$, the eddies amplify as they propagate northward (at an average rate of 40 $\mathrm{km} /$ day) with maximum growth rates occurring just north of the "Charleston bump", a localized topographic irregularity that deflects the Gulf Stream seaward. Brooks and Bane (1981) have demonstrated that the eddy fluctuations are not correlated with wind or coastal sea level, which suggests that their energy comes from hydrodynamic instability of the Gulf Stream front. The observed energy transformations and recent model results indicate that the primary source is the potential energy of the stream (i.e. baroclinic instability) and that the loss of the stabilizing effect of the steep shelf edge topography causes the enhanced growth rates north of the Charleston bump (Dewar and Bane, 1985).

After leaving the continental margin at Cape Hatteras, the dominant mode of instability of the more "jetlike" Gulf Stream shifts to larger-scale, lower-frequency meanders of the entire current. These meanders often amplify and "pinch-off" to form both cold- and warm-core rings on the southern and northern sides of the Stream respectively. Figure 1 shows a typical WCR formation off Cape Cod. Such WCRs were first observed by Jonathan Williams, the grandnephew of Benjamin Franklin, in 1790. In the 1930s, Iselin (1936) made numerous hydrographic observations of isolated WCRs, but their formation from a growing meander was not observed until the 1950s (Fuglister and Worthington, 1951). The influence of rings and meanders on the coastal waters of the Scotian Shelf was noted by McLellan et al. (1953), who pointed out that the position of the narrow boundary separating shelf and slope waters varied "unsystematically" by as much as $250 \mathrm{~km}$ in the region south of Halifax, Nova Scotia, Canada. More recently, Smith (1978) described how tongues of Scotian Shelf water may be drawn offshore by WCRs that approach the shelf, and calculated that such largescale exchanges, at the observed rate of six per year, have a significant impact on the heat, salt and nutrient budgets for the shelf waters. Using a simple box model, Houghton et al. (1978) have shown that measured lowfrequency fluxes at the Scotian Shelf break are capable of supporting the observed alongshore gradients in temperature and salinity as well as the biological

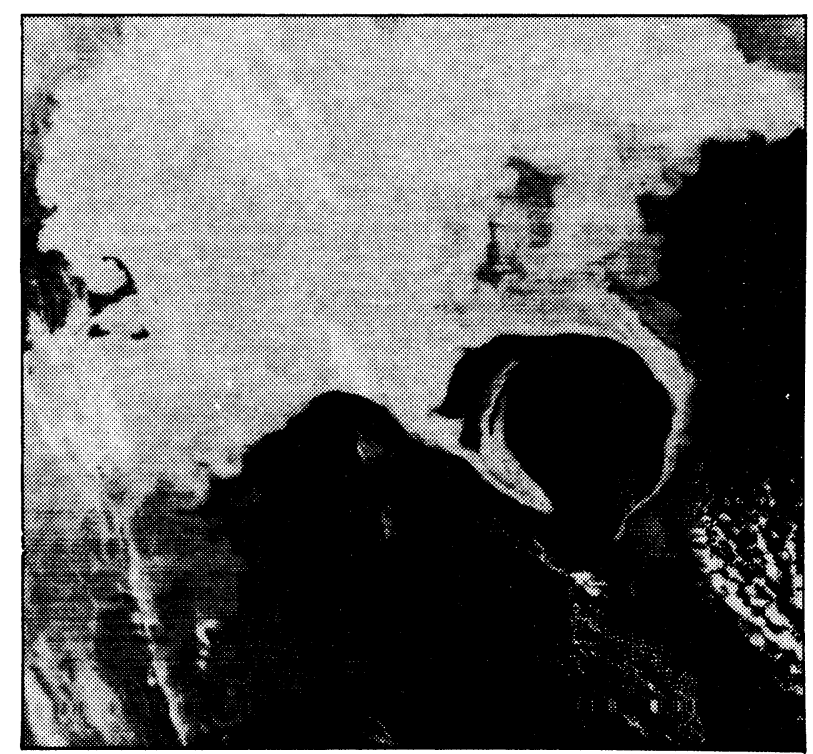

Fig. 1. A satellite infrared image showing the interaction between a warm-core Gulf Stream ring (dark) and colder surface shelf water (light) off Cape Cod, Massachusetts, USA. 
requirements for nitrogen, which has been described (Fournier et al., 1977) as the single most important nutrient supporting primary production on the Shelf.

In the deeper layers, the clockwise circulation of a WCR interacts with the shoaling topography of the continental rise to generate TRWs which radiate energy away from the ring. The properties of linear, inviscid TRW were originally explored theoretically by Rhines (1970) and confirmed by a series of long-term current meter measurements on the New England continental rise by Thompson (1977). Theories have also
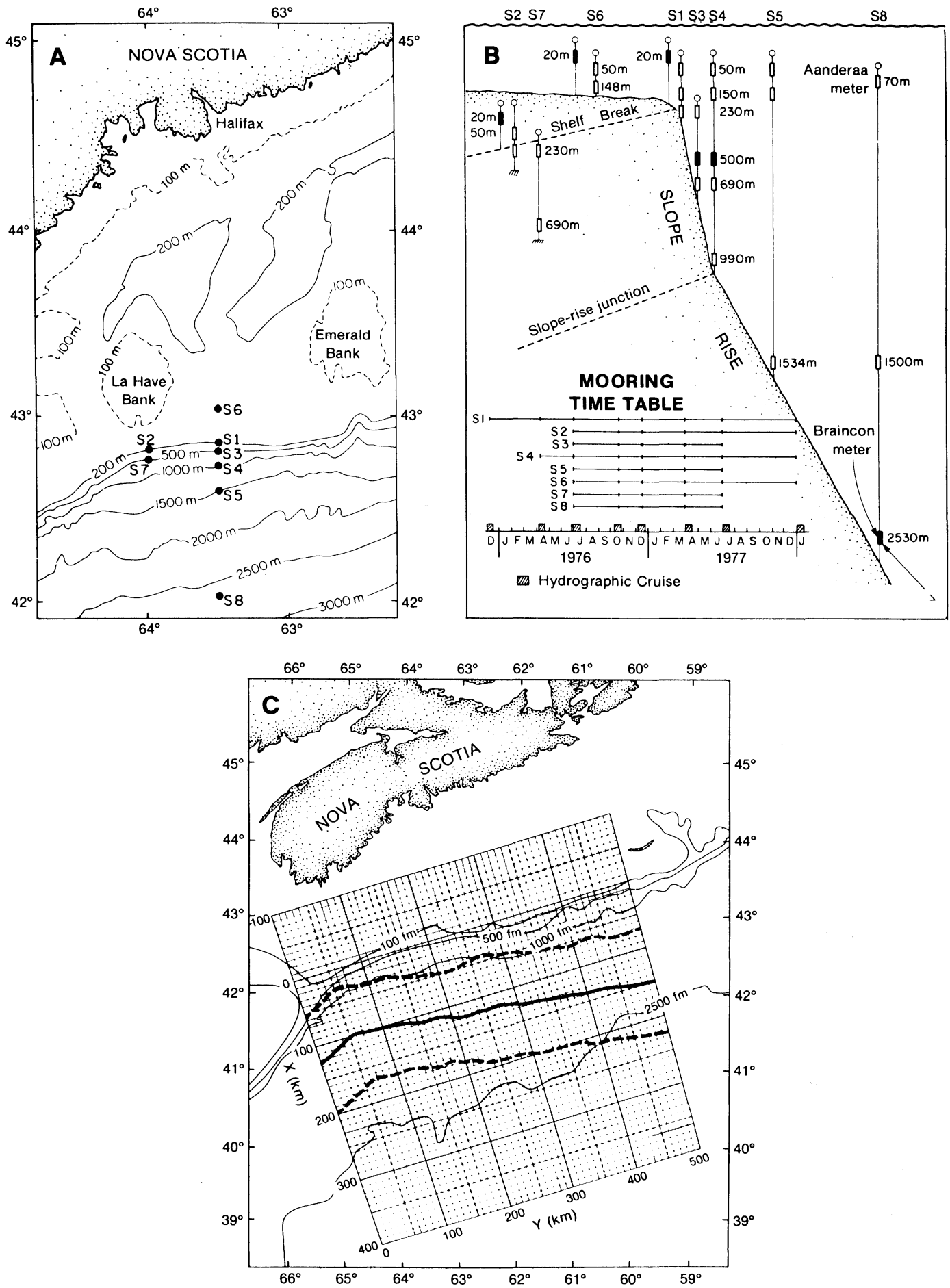

Fig. 2. The monitoring networks for the BIO Shelf Break Experiment off Nova Scotia from December 1975 to January 1978. (A) Mooring array, (B) timetable, (C) $10 \times 10 \mathrm{~km}$ grid used to digitize the positions of sea surface temperature fronts. Mean position (solid) and standard deviation (dashed) of the shelf/slope water boundary are shown for the period of the experiment. 
been developed for the transmission and reflection of TRW energy on the steep continental rise and slope (Kroll and Niiler, 1976) and for the scattering of some of that energy into trapped baroclinic waves ("fringe modes") at a sharp change in topography such as the shelf break (Ou and Beardsley, 1980).

Although these simple models presume that the energy source for the TRW is the Gulf Stream, direct evidence for a generation mechanism was not obtained until 1976-77 during an experiment conducted at the shelf break south of Halifax (Smith and Petrie, 1982). Important elements of this Shelf Break Experiment (Bedford Institute of Oceanography, December 1975 to January 1978) were an array of 11 moorings at 8 sites (Fig. 2A, B) and a series of weekly sea surface frontal analyses based on satellite infrared imagery which were digitized on a $10 \times 10 \mathrm{~km}$ grid oriented to the shelf break (Fig. 2C). The major fronts revealed by the imagery include the north wall of the Gulf Stream, the edges of WCRs, and the shelf/slope water boundary. The shelf/slope boundary shows a $5^{\circ}$ to $8^{\circ} \mathrm{C}$ contrast between coastal and offshore waters which lies roughly $100 \mathrm{~km}$ off the shelf in this region. During July/October, 1976, near bottom records of alongshore current (Fig. 3) revealed a burst of topographic wave energy in which the period gradually increased and the phase propagated offshore (consistent with onshore energy flux; Louis et al., 1982). Louis and Smith (1982) then forumulated an initial value problem for an isolated circular vorticity disturbance on the Scotian Rise, which explained both the temporal variations in wave period (Fig. 4A) and amplitude (Fig. 4B). As a result, the generation time for this wave packet was identified as week 27, 1976, when the frontal analyses indicated that a WCR known as Eddy I was forming $200 \mathrm{~km}$ south of

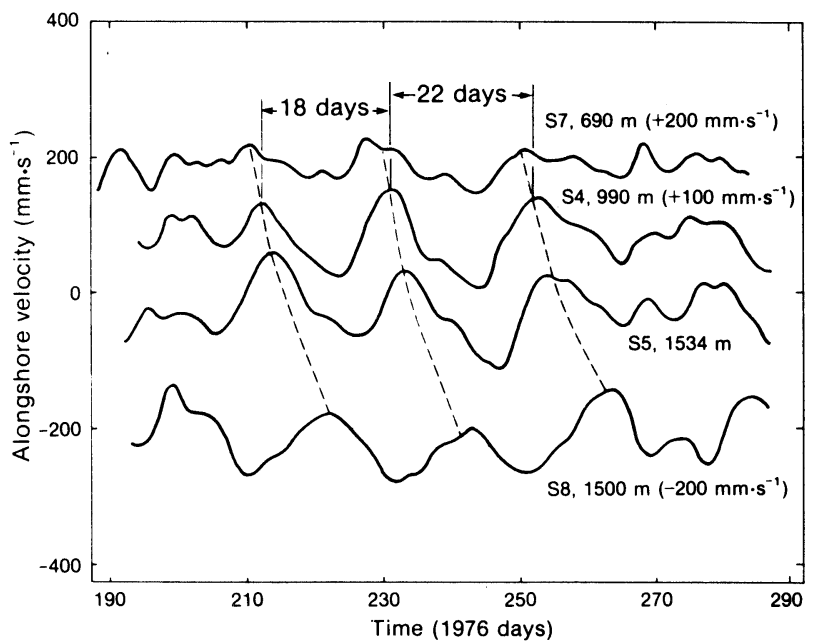

Fig. 3. Filtered records of the alongshore (eastward) current at deep instruments in the offshore region (see Fig. 2) during July through October, 1976. Dashed lines indicate offshore phase propagation; period variations are shown for the S4 record. Week 27 (see Fig. 4 and 5) ends on day 189, 1976. the array (Fig. 5), and the scale of the vorticity disturbance beneath the ring was estimated to be $70 \mathrm{~km}$. Analysis of the three-dimensional TRW energy flux over realistic topography indicated that the strength of low-frequency current oscillations at the shelf break was determined by competition between the amplifying effects of shoaling and refraction versus decay due to radial spreading of the energy. For reasonable estimates of bottom frictional dissipation, the wave energy reaching the shelf edge is expected to decay over alongshore scales of $100 \mathrm{~km}$, so that the disturbances caused by WCR are localized to that extent (Smith, 1983)
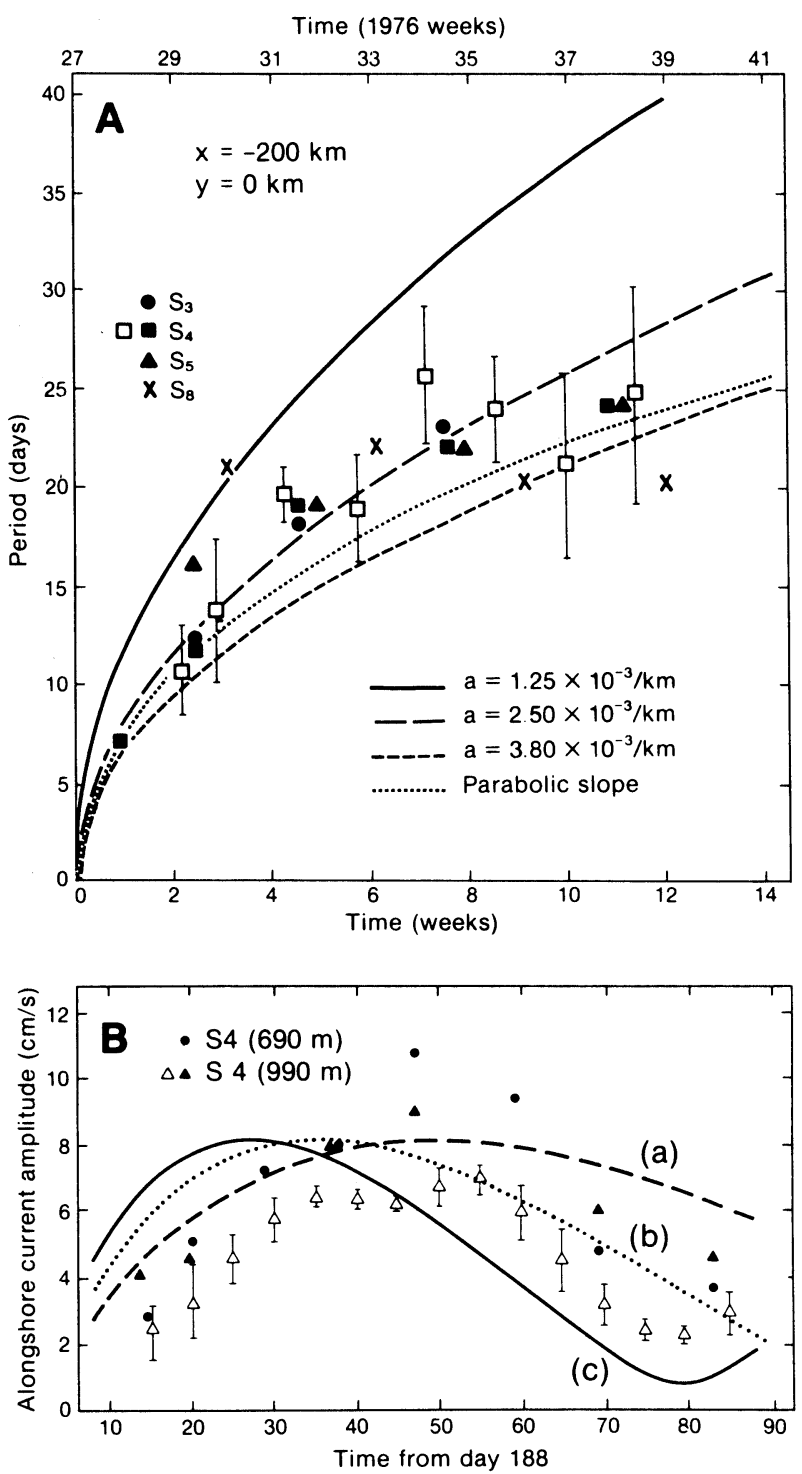

Fig. 4. (A) The observed (symbols) and model (curves) wave period versus time for topographic wave oscillations $200 \mathrm{~km}$ north of the initial disturbance. Curves represent various definitions of model topography. (B) The observed (symbols) and model (curves) wave amplitude variations at the $\mathrm{S} 4$ mooring site (Fig. 2A). Best model fit is achieved for an initial disturbance with a diameter of $70 \mathrm{~km}$ (dotted curve). 

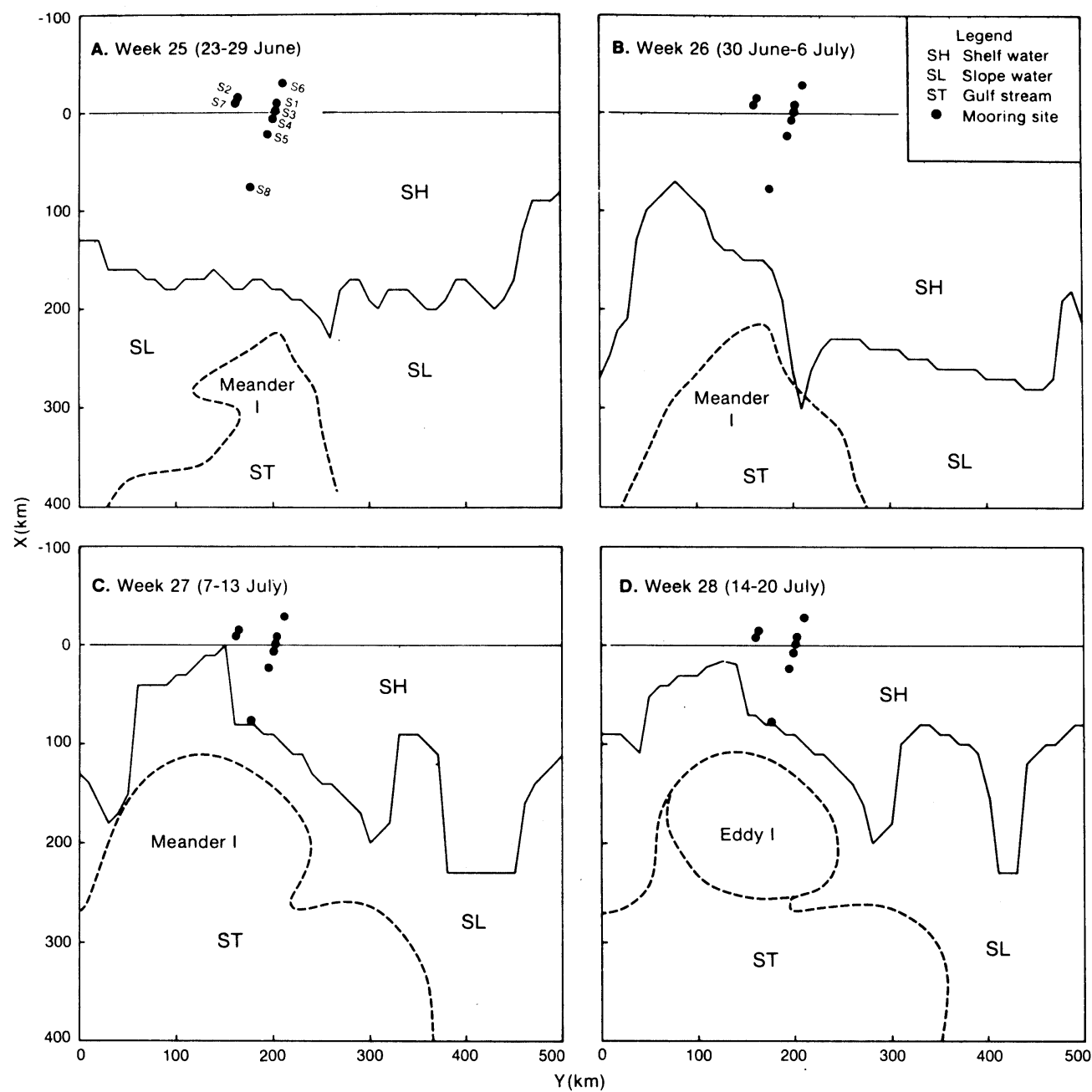

Fig. 5. Frontal analysis of sea surface temperature depicting shelf/slope water boundary (solid) and north wall of the Gulf Stream (dashed) on a rectangular grid with one axis roughly coincident with the shelf break (Fig. 2C). (A-D illustrate the formation and development of Eddy I during weeks 25 to 28 of 1976.)

With regard to their influence on the shelf circulation, Garrett (1979) has shown that the strong TRW currents at the shelf break are capable of inducing upwelling via the bottom Ekman layer, a process which may contribute to the enhancement of cross-shelf fluxes at low frequencies. However, alongshore wind is also effective at producing shelf-break upwelling at somewhat higher frequencies.

Further north, the Labrador Current flows southward along the edge of the Labrador/Newfoundland Shelf and the Grand Banks as part of the sub-polar gyre in the North Atlantic. Like the Gulf Stream in the South Atlantic Bight, the Labrador Current is co-located with the steepest portion of the continental slope and its meandering produces strong low-frequency variability in the current field. LeBlond (1982) observed this variability at the surface using visual images of the offshore ice margin on the Labrador Shelf taken from a NOAA-5 satellite. He attributes the amplifying undulations, with characteristic periods of 4 days and wavelengths of 75 $\mathrm{km}$, to baroclinic instability of the Labrador Current frontal system. In the offshore region, Allen (1979) found evidence in moored current meter measurements for TRWs propagating shoreward in the deep waters of the continental rise. These fluctuations, at periods of 4-8 days, are similar to those found on the Scotian Rise and may be associated with eddy activity in the Labrador Sea.

\section{Wind-Induced Upwelling}

On a broad continental shelf (i.e. much wider than the typical baroclinic adjustment scale of about $10 \mathrm{~km}$ ), the response to alongshore-wind forcing occurs both at the coast and in the vicinity of sharp changes in the bottom slope such as the shelf break. Since the early seventies many theoretical and experimental investigations have been focussed on the coastal upwelling phenomenon, most notably on the narrow shelves of the west coasts of North and South America where the 
shelf-edge and coastal responses are merged. However, theoretical and particularly observational studies of wind-induced shelf-break upwelling are lacking (Huthnance, 1981).

Using a simple two-dimensional "step-shelf" model, Huthnance (1981) demonstrated that shelfbreak upwelling is caused by a divergence of the offshore flow in the surface layer which is proportional to the large depth change between the shelf and ocean as well as the strength of the forcing. With a similar twolayer model, Csanady (1973) showed that the character of a wind-induced alongshore jet at the shelf break was controlled by the nature of the bottom slope and by stratification. Janowitz and Pietrafesa (1980) have also formulated a model for transient upwelling, which includes both bottom friction and weak stratification. Their results suggest that sufficiently sharp changes in the bottom slope at the shelf break produce a persistent upward bulge in the isopycnals, which implies a vertical shear in the alongshore current according to geostrophic dynamics. Furthermore the strength and timing of this model circulation are in reasonable agreement with measurements in the South Atlantic Bight, where wind-induced upwelling in summer is credited with supplying significant quantities of nutrients to the midshelf region (Atkinson et al., 1982).

On the Scotian Shelf, early hydrographic observations (McLellan et al., 1953; Hachey, 1953) indicated that the Scotian Gulf, which lies between Emerald and LaHave Banks south of Halifax, is a favoured location for wind-driven intrusions of slope water. Petrie and Smith (1977) suggested that such events are capable of flushing the deep waters of Emerald Basin in the autumn and winter. More recently, Petrie (1983) has found evidence in data from the shelf break experiment (Fig. 2) that moderate alongshore winds that last for at least 2 days produce upwelling at the shelf break from depths of $400 \mathrm{~m}$ or more on the continental slope (based on hydrographic properties measured at the shelf break). Peak vertical velocities are about $2 \mathrm{~mm} / \mathrm{s}$ and the upwelling appears to be confined to within 10 $\mathrm{km}$ of the slope. Furthermore, the vertical alongshore current shear and horizontal density gradients at the shelf break were found to be in geostrophic balance. On the shelf, however, large anomalous bottom currents with maxima near $1 \mathrm{~m} / \mathrm{s}$ (Fig. 6) are attributed to local topographic variations on the outer banks. Although the four dominant episodes of onshore flow (commencing on days 289, 312, 325 and 338) correspond to periods of persistent (10-15 $\mathrm{m} \mathrm{s}^{-1}$ for 2-4 days) alongshore winds at Sable Island, Petrie's (1983) attempts to model the transient current fields with twodimensional analytical and numerical models failed both quantitatively and qualitatively. Thus, he concluded that in the presence of complex topography, the wind-driven response at the shelf break is essentially three-dimensional.

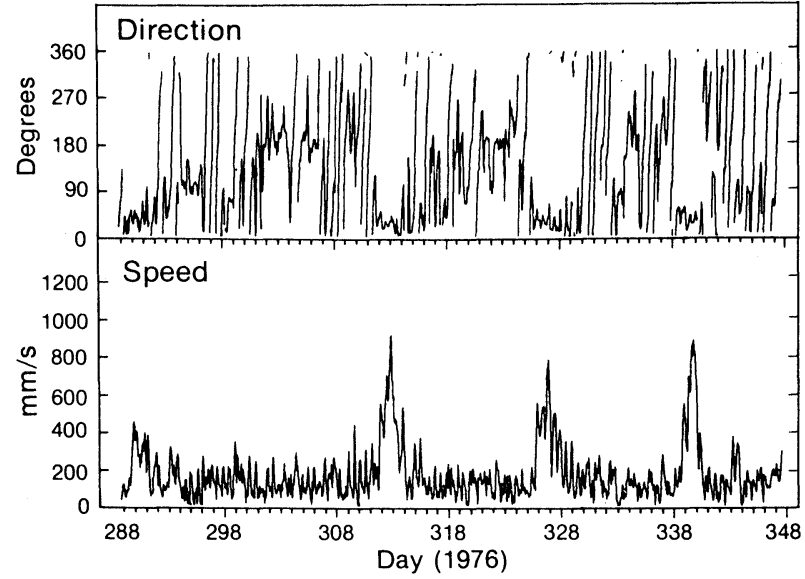

Fig. 6. A time series of speed and direction of near bottom currents taken from the shelf mooring at site S6 (Fig. 2A) at a depth of $148 \mathrm{~m}$ during October through December 1976.

The Labrador and Newfoundland shelves also have complex topography characterized by numerous banks and saddles. Hence, shelf-break upwelling in these regions is also expected to be a threedimensional phenomenon. Here an additional complication is introduced by the presence of the Labrador Current front which serves to enhance cross-shelfexchange induced by upwelling-favourable winds (Ikeda, 1985).

\section{Internal Tide and Nonlinear Waves}

Low-frequency shoreward fluxes of nutrients, which appear to support biological productivity at the shelf break, are concentrated from mid-depths to the bottom. An important question that arises with regard to this is: how do they reach the euphotic zone? One likely mechanism is vertical mixing caused by internal waves.

The rapid development of many new techniques and instruments (e.g. the Ekman current meter) in the early 1900's by Scandinavian oceanographers, who were stimulated by the need to know more about large fluctuations in the food supply for fish, led to the discovery of internal waves. Nansen (1902) was the first to observe internal waves in the ocean, but it took Ekman's (1904) model calculations to identify them. Many more observations of internal waves followed, and Fjeldstad (1933) extended the dynamical theory from the early layered models to a continuously stratified fluid.

By 1960 , despite a large volume of literature on internal waves, little was known about their generation and distribution in the ocean. Then Rattray (1960) used a simple two-layer, step-shelf model to demonstrate coupling between the surface and internal tides, but it was Cox and Sandström (1962) who calculated the rate 
of energy flow from surface to internal tides, by scattering from bottom roughness in a continuously stratified ocean. This paper has since become a cornerstone in the study of deep ocean internal tides. The early sixties also saw the first applications of optical ray theory to oceanographic problems (Sandström, 1966). This technique has formed the basis for many important subsequent investigations of the interaction between surface and internal tides (Baines, 1974; Prinsenberg and Rattray, 1975). According to Baines' model, the most efficient conversion of energy occurs where the local topographic slope and the ray slope of the internal tide are equal. This condition is generally met at the shelf edge. To generalize these results, Sandström (1976) formulated a unified ray theory with which he explored the sensitivity of the topographic generation problem to variations in stratification and bottom topography.

Observational studies of the internal tide in the seventies benefited both from these theoretical advances and new instrumentation of the 1960s. For example, both Warner (1970) and Petrie (1975) gained insight by analyzing moored current and temperature measurements on the Scotian Shelf and Slope. Petrie, in particular, demonstrated that the intersections of critical rays from generation sites at the shelf break with the moorings were consistent with the observed structure of the M2 internal tide. In the St. Lawrence estuary Forrester's (1973) examination of hydrographic variability clarified the role of internal tides generated at the head of the Laurentian Channel.

In the 1980s, internal tide research has been spurred first by the realization that internal tides cause or enhance fine and microstructure events related to ocean mixing, and second by the discovery of finiteamplitude, short internal waves (solitons, internal bores), which are somehow related to the internal tide. Groups of these short-period (e.g. $10 \mathrm{~min}$ ) waves have been detected at certain phases of the $M_{2}$ tide in many locations, usually with temperature measurements e.g. in the Strait of Gibraltar by Ziegenbein (1969), in Massachusetts Bay by Haury et al. (1979), in British Columbia fjords by Farmer and Smith (1980) and, more recently, on the shelves of northern Europe by Pingree and Mardell (1985), who emphasized their biological importance. These studies have benefited considerably from the development of remote sensing techniques to study the ocean from satellite, aircraft and shipboard platforms.

In 1980, Canadian scientists commenced a multiyear investigation of the relationships between tides, turbulence, and ocean mixing at the edge of the Scotian Shelf, in order to understand the reasons for high nutrient concentrations and biological productivity in the euphotic zone (Sandström and Elliott, 1984). Additionally, observations have been made all along the Scotian Shelf and Grand Banks to map the occurrence

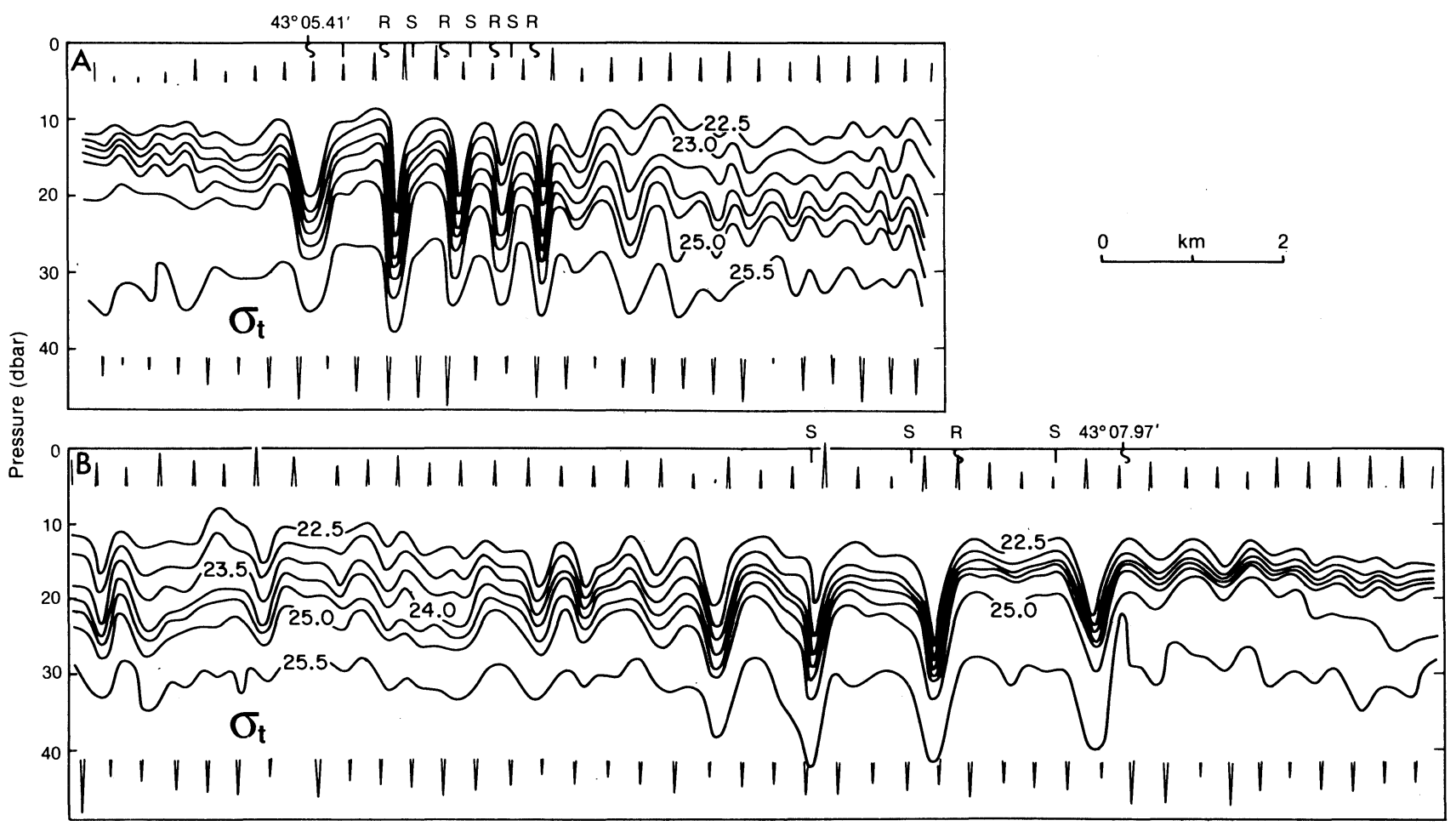

Fig. 7. The density field observed by BATFISH for two consecutive crossings of a short internal wave packet: (A) ship and waves travelling in opposite directions; (B) ship overtaking the waves. A banded pattern observed at the surface is marked as $R=$ rough and $S=s m o o t h$. The ship track lies along $63^{\circ} 30^{\prime} \mathrm{W}$ longitude in a region just shoreward of the shelf break. (The vertical arrowheads represent the extremities of the BATFISH path.) 


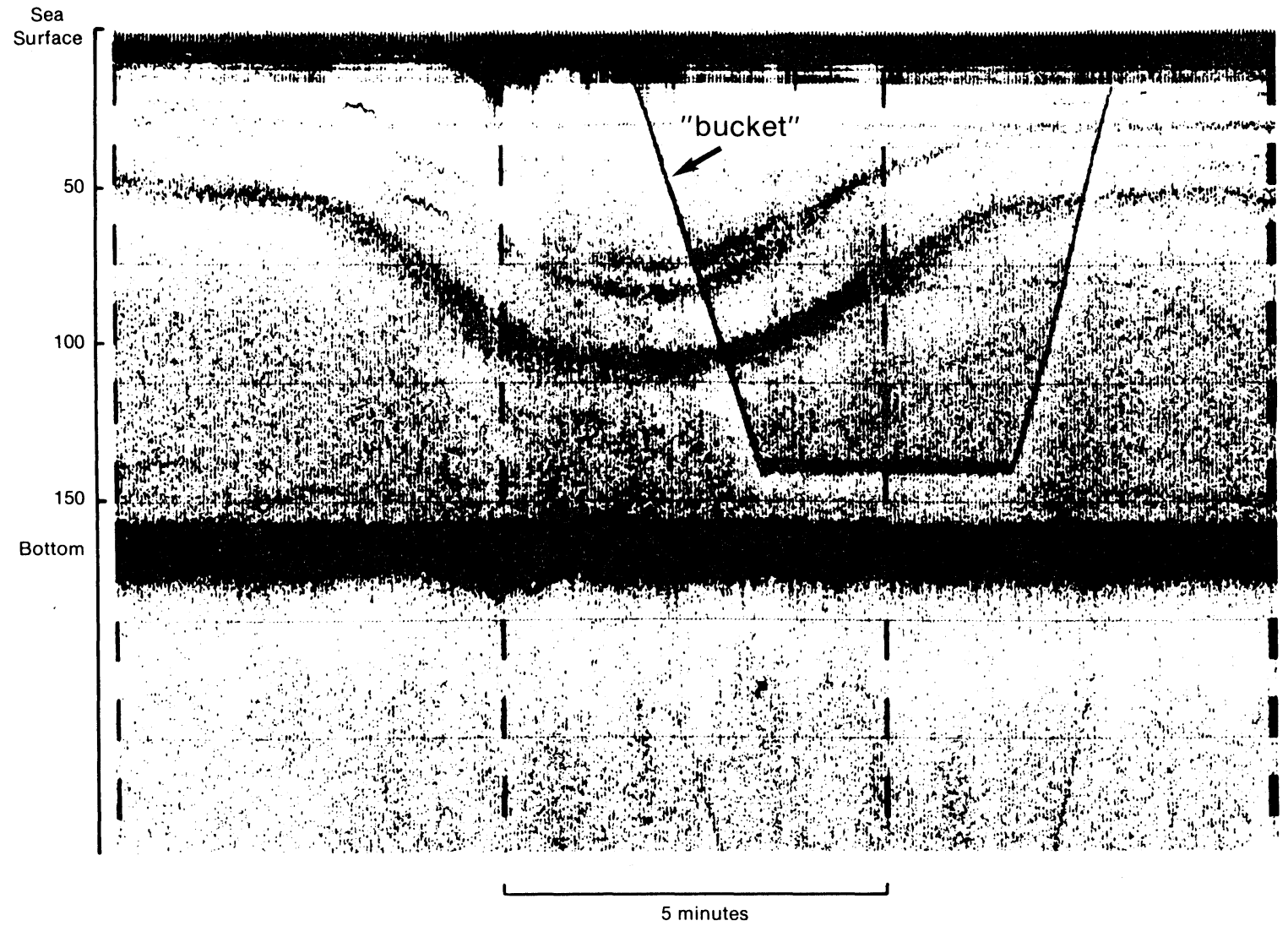

Fig. 8. An internal soliton on the shelf as seen by a $12-\mathrm{kHz}$ acoustic sounder on a ship drifting at $63^{\circ} 30^{\prime} \mathrm{W}$ just shoreward of the shelf break. (The "bucket" is the trace of CTD package traversing the water column.)

and nature of the large amplitude waves. In conjunction with the field program, theoretical studies of the connection between the internal tide and ocean mixing are continuing. Much of the recent progress in this work is possible with towed undulating bodies such as BATFISH (Dessureault, 1976), which are used to survey hydrographic properties in the surface layer as those shown in Fig. 7. Acoustic sounding systems using single or multiple frequencies have also been used to provide high resolution images of short internal waves (Fig. 8) at the shelf break, while rapid sampling turbulence probles (Oakey, 1983) serve to quantify ocean microstructure and dissipation rates.

Packets of short internal waves have been detected as far north as Davis Strait (Cummins and LeBlond, 1984) which, in conjunction with theoretical predictions, indicates that they are a ubiquitous feature of the continental shelf break circulation in the western North Atlantic.

\section{Conclusions}

There has been rapid progress in understanding three distinct physical processes at the shelf break over the last two decades. The low-frequency forcing of the shelf break circulation by strong western boundary currents and mesoscale eddies occur in the USA South
Atlantic Bight, where the Gulf Stream itself meanders onto the shelf, and on the Labrador/Newfoundland Shelf, where the Labrador Current flows along the shelf break. In contrast, WCR and meanders radiate lowfrequency TRWs to the Scotian Shelf break and promote mixing across the shelf/slope water boundary. Wind-induced upwelling at the edge of the Scotian Shelf results in exceptionally strong bottom currents as a result of the complex topography on the outer banks while the presence of the Labrador Current front at the shelf break promotes cross-shelf mixing by wind. These and advances in our knowledge of the internal tide and large-amplitude internal waves at the shelf break promise to lead to a clearer understanding of oceanic mixing as it relates to biological productivity on the continental shelf.

\section{References}

ALLEN, A. A. 1979. Current variability at the offshore edge of the Labrador Current. M.Sc. Thesis, Dalhousie Univ., Halifax, N. S., 164 p.

ATKINSON, L. P., L. J. PIETRAFESA, and E. E. HOFMANN. 1982. An evaluation of nutrient sources to Onslow Bay, North Carolina. J. Mar. Res., 40: 679-699.

BAINES, 'P. G. 1974. The generation of internal tides over steep continental slopes. Philos. Trans. Roy. Soc. Lond. 
(Ser. A), 277: 27-58.

BANE, J. M., D. A. BROOKS, and K. R. LORENSEN. 1981. Synoptic observations of the three-dimensional structure, propagation and evolution of Gulf Stream meanders along the Carolina continental margin. J. Geophys. Res., 86: 6411-6425.

BROOKS, D., and J. M. BANE. 1981. Gulf Stream fluctuations and meanders over the Onslow Bay upper continental slope. J. Phys. Oceanogr., 11: 247-256.

COX, C. S., and H. SANDSTRÖM. 1962. Coupling of internal and surface waves in water of variable depth. J. Oceanogr. Soc. Japan, 20th. Anniv. Vol.: 419-513.

CSANADY, G. T. 1973. Wind-induced baroclinic motions at the edge of the continental shelf. J. Phys. Oceanogr., 3: 274-279.

CUMMINS, P. F., and P. H. LEBLOND. 1984. Analysis of internal solitary waves observed in Davis Strait. AtmosphereOcean, 22: 173-192.

DESSUREAULT, J.-G. 1976. "Batfish". A depth controllable towed body for collecting oceanographic data. Oceanogr. Eng., 3: 99-111.

DEWAR, W. K., and J. M. BANE,1985. Subsurface energetics of the Gulf Stream near the Charleston bump. J. Phys. Oceanogr., 15: 1771-1789.

EKMAN, V. W. 1904. On dead water. Sci. Res. Norweg. N. Pol. Exped. 1893-96, 5(15): $152 \mathrm{p}$.

FARMER, D. M., and J. D. SMITH. 1980. Tidal interaction of stratifed flow with a sill in Knight Inlet. Deep-Sea Res., 27: 239-254.

FJELDSTAD, J. E. 1933. Interne Wellen. Geofys. Publ., 10(6): $35 \mathrm{p}$.

FORRESTER, W. D. 1973. Internal tides in St. Lawrence Estuary. J. Mar. Res., 32: 55-66.

FOURNIER, R. O., J. MARRA, R. BOHRER, and M. VAN DET. 1977. Plankton dynamics and nutrient enrichment of the Scotian Shelf. J. Fish. Res. Board Can., 34: 1004-1018.

FUGLISTER, F. C., and L. V. WORTHINGTON. 1951. Some results of a multiple ship survey of the Gulf Stream. Tellus, 3: $1-14$.

GARRETT, C. 1979. Topographic waves off East Australia: Identification and role in shelf circulation. J. Phys. Oceanogr. 9: 244-253.

HACHEY, H. B. 1953. A winter incursion of slope water on the Scotian Shelf. J. Fish. Res. Board Can., 10: 148-153.

HAURY, L. R., M. G. BRISCOE, and M. H. ORR. 1979. Tidallygenerated internal wave packets in Massachusetts Bay. Nature, 278: 312-317.

HOUGHTON, R. W., P. C. SMITH, and R. O. FOURNIER. 1978. A simple box model for cross-shelf mixing on the Scotian Shelf. J. Fish. Res. Board Can., 35: 414-421.

HUTHNANCE, J. M. 1981. Waves and currents near the continental shelf edge. Progr. Oceanogr., 10: 193-226.

IKEDA, MOTOYOSHI. 1985. Wind effects on a front over the continental shelf slope. J. Geophys. Res., 90: 9108-9118.

ISELIN, CO'D. 1936. A study of the circulation on the western North Atlantic. Pap. Phys. Oceanogr. Meteor., 4(4): 101 p.

JANOWITZ, G. S., and L. J. PIETRAFESA. 1980. A model and observations of time-dependent upwelling over the midshelf and slope. J. Phys. Oceanogr., 10: 1574-1583.

KROLL, J., and P. P. NIILER. 1976. The transmission and decay of barotropic topographic Rossby waves incident on a continental shelf. J. Phys. Oceanogr., 6: 432-450.

LEBLOND, P. H. 1982. Satellite observations of Labrador Current undulations. Atmosphere-Ocean, 20: 129-142.

LEE, T. N., L. P. ATKINSON, and R. LEGECKIS. 1981. Obser- vations of a Gulf Stream frontal eddy on the Georgian continental shelf, April 1977. Deep-Sea Res., 28: 347-378.

LOUIS, J. P., and P. C. SMITH. 1982. The development of the barotropic radiation field of an eddy over a slope. J. Phys. Oceanogr., 12: 56-73.

LOUIS, J. P., B. D. PETRIE, and P. C. SMITH. 1982. Observations of topographic Rossby waves on the continental margin off Nova Scotia. J. Phys. Oceanogr., 12: 47-55.

McLELLAN, H. J., L. M. LAUZIER, and W. B. BAILEY. 1953. The slope water off the Scotian Shelf. J. Fish. Res. Board Can., 10: 155-176.

NANSEN, F. 1902. The Oceanography of the North Polar Basin. Sci. Res. Norweg. N. Pol. Exped. 1893-96, 3(9): $427 \mathrm{p}$.

OAKEY, N. S. 1983. Near surface turbulence measurements. In: BIO Review '83. Bedford Institute of Oceanography, Dartmouth, Nova Scotia, Canada, p. 46-47.

OU, H. W., and R. C. BEARDSLEY. 1980. On the propagation of free topographic Rossby waves near continental margins. Part 2: Numerical model. J. Phys. Oceanogr., 10: 1323-1339.

PETRIE, B. D. 1975. M2 surface and internal tides on the Scotian Shelf and Slope. J. Mar. Res., 33: 303-323.

1983. Current response at the shelf break to transient wind forcing. J. Geophys. Res., 88: 9567-9578.

PETRIE, B. D., and P. C. SMITH. 1977. Low-frequency motions on the Scotian Shelf and Slope. Atmosphere, 15: 117-140.

PINGREE, R. D. 1979. Baroclinic eddies bordering the Celtic Sea in late summer. J. Mar. Biol. Assoc. U.K., 59:689-698.

PINGREE, R. D., and G. T. MARDELL. 1985. Solitary internal waves in the Celtic Sea. Progr. Oceanogr., 14: 431-441.

PRINSENBERG, S. J., and M. RATTRAY, Jr. 1975. Effects of continental slope and variable Brunt-Vaisala frequency on the coastal generation of internal tides. Deep-Sea Res., 22: 251-263.

RATTRAY, M., Jr. 1960. On the coastal generation of internal tides. Tellus, 12: 54-62.

RHINES, P. B. 1970. Edge-, bottom-, and Rossby waves in a rotating stratified fluid. Geophys. FI. Dynam., 1: 273-302.

SANDSTRÖM, H. 1966. The importance of topography in generation and propagation of internal waves. Ph.D. Thesis, Univ. of California at San Diego, San Diego, CA, 105 p.

1976. On topographic generation and coupling of internal waves. Geophys. FI. Dynam., 7: 231-270.

SANDSTRÖM, H., and J. A. ELLIOTT. 1984. Internal tide and solitons on the Scotian Shelf: A nutrient pump at work. J. Geophys. Res., 89: 6415-6426.

SMITH, P. C. 1978. Low-frequency fluxes of momentum, heat, salt and nutrients at the edge of the Scotian Shelf. J. Geophys. Res., 83: 4079-4096.

1983. Eddies and coastal interactions. In: Eddies in Marine Science, A. R. Robinson (ed.), Springer-Verlag, Berlin, Heidelberg and New York, 609 p.

SMITH, P. C., and B. D. PETRIE. 1982. Low-frequency circulation at the edge of the Scotian Shelf. J. Phys. Oceanogr., 12: $28-46$.

THOMPSON, R. 1977. Observations of Rossby waves near site D. Progr. Oceanogr., 7: 135-162.

WARNER, J. L. 1970. Water movement on the Scotian Shelf. Ph.D. Thesis, Dalhousie Univ., Halifax, N. S., 277 p.

WEBSTER, F. 1961. A description of Gulf Stream meanders off Onslow Bay. Deep-Sea Res., 8: 130-143.

ZIEGENBEIN, J. 1969. Short internal waves in the Strait of Gibraltar. Deep-Sea Res., 16: 479-489. 
